\title{
CrimRxiv
}

\section{Collaborating Against Child Abuse: Exploring the Nordic Barnahus Model}

Susanna Johansson, Kari Stefansen, Elisiv Bakketeig, Anna Kaldal

Published on: Jul 01, 2017

DOI: 10.21428/cb6ab371.ba468ca5

License: Creative Commons Attribution 4.0 International License (CC-BY 4.0). 
